\title{
Alternating Copolymerization of Polar Olefins with Carbon Monoxide
}

\author{
Kyoko Nozaki \\ Department of Chemistry and Biotechnology, Graduate School of Engineering, \\ The University of Tokyo
}

(Received July 9, 2007)

\begin{abstract}
Palladium-catalyzed alternating copolymerization of olefins with carbon monoxide has been successfully applied to new substrates, namely, 3-perfluoroalkyl-substituted 1-propene (1) and vinyl acetate. The key to success was the choice of ligands. The bulky phosphine-phosphite ligand, $(R, S)$-BINAPHOS (2e) realized the 1,2-insertion of $\mathbf{1 a}, \mathbf{b}$ to enable the subsequent $\mathrm{CO}$ insertion. With phosphine-sulfonate ligand 7a, the first example of the alternating copolymerization of vinyl acetate with $\mathrm{CO}$ has been performed via $\mathrm{CO}$ insertion to the stable chelation intermediate which has never been performed with the conventional ligands for the copolymerization.
\end{abstract}

\section{Introduction}

Coordination polymerization has played a major role in the field of polymer synthesis since linear polyethylene and isotactic polypropylene were provided by the discovery of the Ziegler-Natta catalyst. The metallocene and post-metallocene catalysts further expanded the variety of available polymers. In spite of the considerable efforts devoted, however, efficient polymerization of functionalized monomers still remains a challenging target because functional groups in monomers often coordinate with metal catalysts to retard polymerization. ${ }^{1}$ The alternating copolymerization of olefins with carbon monoxide catalyzed by late transition-metals such as palladium(II) catalysts, is one of the best methods for efficient synthesis of polar functionalized polymers by coordination polymerization of olefins. ${ }^{2}$

The copolymerization reaction clearly demonstrates the functional group tolerance of palladium(II) catalysts, because it proceeds in the presence of numerous carbonyl groups incorporated in the resulting $\gamma$-polyketones. In facl, several olefins bearing functional groups were applied to the copolymerization represented as $\mathrm{CH}_{2}=\mathrm{CH}-\mathrm{X}$ where $\mathrm{X}$ is $\mathrm{CH}_{2} \mathrm{CH}_{2} \mathrm{OH},{ }^{3} \mathrm{CH}_{2} \mathrm{COOH},{ }^{3} \mathrm{CH}_{2} \mathrm{OR},{ }^{4} \mathrm{CH}_{2} \mathrm{C}_{6} \mathrm{~F}_{5}{ }^{5}$ and $\mathrm{CH}_{2} \mathrm{CH}_{2} \mathrm{C}_{4} \mathrm{~F}_{9}{ }^{6}{ }^{6}$ On the contrary, mono-substituted ethenes directly functionalized on the $\mathrm{C}-\mathrm{C}$ double bond, such as methyl acrylate, ${ }^{7}$ vinyl acetate,${ }^{8}$ and vinyl chloride, ${ }^{9}$ were reported to be unfavorable for the alternating copolymerization with carbon monoxide. Here reviewed is our recent development on the olefin/CO alternating copolymerization employing two kinds of polar olefins, those are 3-perfluoroalkyl-1-propene and vinyl acetate. Both of the substrates have a common problem to overcome in order to perform the efficient copolymerization. The key for our success was the choice of ligands.

As shown in Scheme 1, the copolymerization would take place via olefin coordination with acylpalladium $(\mathbf{A} \rightarrow \mathbf{B})$, intramolecular olefin insertion $(\mathbf{B} \rightarrow \mathbf{C})$, carbon monoxide coordination $(\mathbf{C} \rightarrow \mathbf{D})$, and intramolecular CO insertion (D $\rightarrow \mathbf{A})$. The coordination of olefins $(\mathbf{A} \rightarrow \mathbf{B})$ is reported to be less favorable for $\mathrm{X}=\mathrm{OCOCH}_{3}, \mathrm{Cl}$, and $\mathrm{CN}$ when compared to ethene or simple 1-alkenes. ${ }^{7-9}$ Nevertheless, for acetylpalladium complexes, the olefin insertion $(\mathbf{B} \rightarrow \mathbf{C})$ was reported to proceed for $\mathrm{X}=\mathrm{COOMe},{ }^{10,11} \mathrm{OCOCH}_{3},{ }^{11}$ and $\mathrm{Cl} .{ }^{12}$ The insertion occurs via the predominant 2,1-insertion in all the reported examples. Alkylpalladium $\mathbf{C}$ thus produced has an electronegative group $\mathrm{X}$ on the $\alpha$-carbon of palladium. The electronegative group in $\mathbf{C}$ was reported to cause the stronger five-membered chelation of the carbonyl oxygen with the metal center. ${ }^{12}$ Although heteroatoms such as oxygen or chlorine are $\pi$-electron donors, the electron withdrawing nature through the $\sigma$-bond seems to be more influential at this stage at least for $\mathrm{X}=\mathrm{OCOCH}_{3}$ and $\mathrm{Cl}$. This chelation was anticipated to obstruct the subsequent $\mathrm{CO}$ insertion which requires the replacement of the intramolecular ketone-coordination by the intermolecular CO-coordination $(\mathbf{C} \rightarrow \mathbf{D})$. In addition, the electronegative substituent on the $\alpha$-carbon in $\mathbf{D}$ should retard subsequent $\mathrm{CO}$ insertion into the metal-carbon bond ( $\mathbf{D} \rightarrow \mathbf{A}$ ) by lowering the nucleophilicity of the migrating $\alpha$-carbon atom. For example, in a carbonyl complex $\mathrm{L}_{2} \mathrm{Pd}(\mathrm{CO}) \mathrm{R}$ where $\mathrm{L}_{2}$ is a bidentate $\mathrm{sp}^{2}$-nitrogen ligand, the $\mathrm{CO}$ insertion takes place when $\mathrm{R}$ is $\mathrm{CH}_{2} \mathrm{Cl}^{13}$ or CIIEtOCOCH${ }_{3}{ }^{7}$ but does not takes place when $\mathrm{R}$ is $\mathrm{CHCl}_{2}$ or $n^{-} \mathrm{C}_{3} \mathrm{~F}_{7}{ }^{13}\left(\mathrm{~L}_{2}\right.$ is dppp for the last example). As a result, all of the attempted examples for the alternating copolymerization of polar olefins $\left(\mathrm{X}=\mathrm{COOMe},{ }^{10} \mathrm{OCOCH}_{3},{ }^{11}\right.$ and $\mathrm{Cl}^{12}$ ) with $\mathrm{CO}$ ended up at the stage of complex $\mathbf{C}$ when started from an acetylpalladium corresponding to $\mathbf{A}$.

Scheme 1. Possible alternating copolymerization of functionalgroup substituted olefins and carbon monoxide.

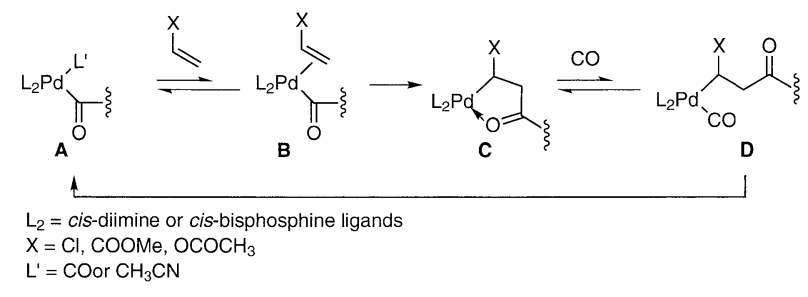

2. The Alternating Copolymerization of Fluorinated Alkenes with Carbon Monoxide

Perfluoroalkyl groups are known as one of the strongest electron-withdrawing groups in organic chemistry. We recently succeeded in the copolymerization of fluoroalkenes repre- 
sented as $\mathrm{CH}_{2}=\mathrm{CH}-\mathrm{CH}_{2}-\mathrm{C}_{\mathrm{n}} \mathrm{F}_{2 \mathrm{n}+1}$ with $\mathrm{CO}$ as described below. ${ }^{14}$ It is of interest to compare the substituents based on their electronegativity. As an index to compare the electronegativity of substituents, the Taft's $\sigma^{*}$ value may be referred to. ${ }^{15}$ The Taft's $\sigma^{*}$ value of 0.90 for $-\mathrm{CH}_{2} \mathrm{CF}_{3}$ is the highest value $^{16}$ when compared to the values of $0.21\left(-\mathrm{CH}_{2} \mathrm{CH}_{2} \mathrm{OH}\right)$, $0.82\left(-\mathrm{CH}_{2} \mathrm{COOEt}\right), 0.58\left(-\mathrm{CH}_{2} \mathrm{OEt}\right)$, and $0.32\left(-\mathrm{CH}_{2} \mathrm{CH}_{2} \mathrm{CF}_{3}\right)$ for the substituents which were applicable to the copolymerization.

By using $\mathrm{Pd}-(R, S)-$ BINAPHOS (2e) system as a catalyst, the alternating copolymer of $\mathrm{CH}_{2}=\mathrm{CHCH}_{2}-n-\mathrm{C}_{8} \mathrm{~F}_{17}$ (1a) and $\mathrm{CO}$ was obtained. The representative results are summarized in Table 1. Within the ligands examined in our study, the use of $2 \mathbf{e}$ gave superior yield to the ones with the other conventional ligands for the alternating olefin/CO copolymerization; the use of conventional ligands for the olefin/CO copolymerization, 2a-2d resulted in the formation of trace amounts of product (runs 1-6 and 10). The yield was improved at the

Scheme 2. The alternating copolymerization of olefins and carbon monoxide catalyzed by the palladium complexes bearing a bidentate ligand.

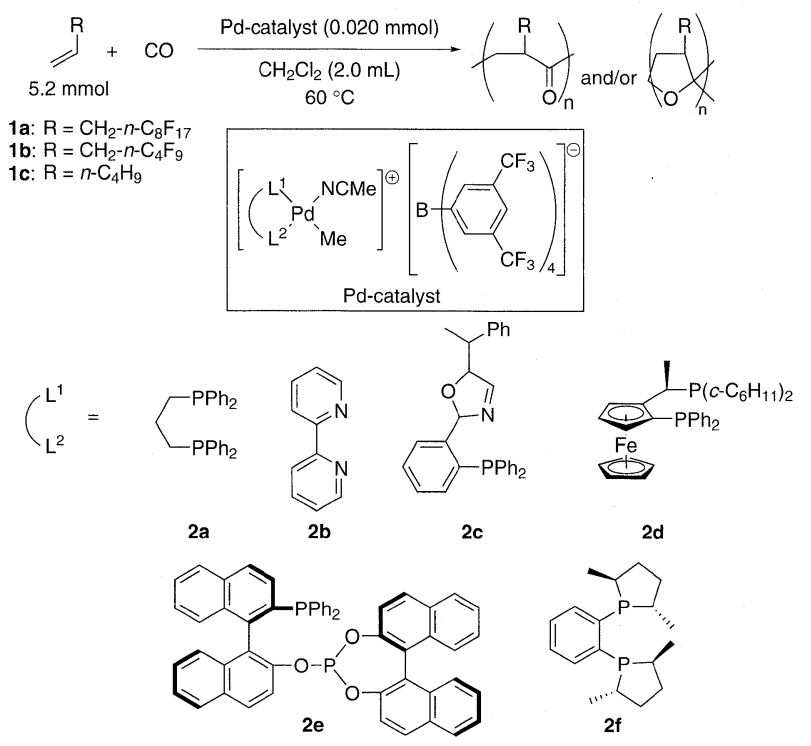

Table 1. The alternating copolymerization of fluorvalkenes 1a with $\mathrm{CO}^{\prime}$.

\begin{tabular}{ccccr}
\hline run & $\begin{array}{c}\text { Ligand } \\
\mathrm{L}^{1}-\mathrm{L}^{2}\end{array}$ & $\begin{array}{c}\mathrm{P}_{\mathrm{CO}} \\
(\mathrm{MPa})\end{array}$ & $\begin{array}{c}\text { Time } \\
(\mathrm{h})\end{array}$ & Yield \\
\hline 1 & $\mathbf{2 a}$ & 3.0 & 24 & 3 \\
2 & $\mathbf{2 a}$ & 8.0 & 24 & 3 \\
3 & $\mathbf{2 b}$ & 3.0 & 17 & 2 \\
4 & $\mathbf{2 c}$ & 3.0 & 40 & 0 \\
5 & $\mathbf{2 d}$ & 3.0 & 24 & 5 \\
6 & $\mathbf{2 e}$ & 3.0 & 24 & 27 \\
7 & $\mathbf{2 e}$ & 5.0 & 24 & 49 \\
8 & $\mathbf{2 e}$ & 8.0 & 24 & 54 \\
9 & $\mathbf{2 e}$ & 8.0 & 84 & 81 \\
10 & $\mathbf{2 f}$ & 3.0 & 24 & 8 \\
11 & $\mathbf{2 f}$ & 5.0 & 24 & 27 \\
12 & $\mathbf{2 f}$ & 8.0 & 24 & 34 \\
\hline
\end{tabular}

${ }^{a} \mathrm{Pd}(0.020 \mathrm{mmol})$, alkene $(5.2 \mathrm{mmol})$ in $\mathrm{CH}_{2} \mathrm{Cl}_{2}(2$ $\mathrm{mL}$ ) at $60{ }^{\circ} \mathrm{C}$ (Palladium complexes were prepared by the reaction of (cod) $\mathrm{PdMeCl}$ with ligands $\mathbf{2 a - 2 f}$ in toluene and then with $\mathrm{Na}\left[\mathrm{B}\left(3,5-\left(\mathrm{CF}_{3}\right)_{2} \mathrm{C}_{6} \mathrm{H}_{3}\right)_{4}\right]$ in $\mathrm{MeCN} / \mathrm{CH}_{2} \mathrm{Cl}_{2}$. higher CO pressure (runs 6-8), and the highest yield of $81 \%$ was achieved under $\mathrm{CO}$ pressure of $8.0 \mathrm{MPa}$ in $84 \mathrm{~h}$ (run 9). A similar pressure effect was observed with MeDuPHOS (2f), which was previously reported as an effective ligand for polymerization of $\mathrm{CH}_{2}=\mathrm{CHCH}_{2} \mathrm{C}_{6} \mathrm{~F}_{5},{ }^{5}$ although the yields were slightly lower than those with 2 e (runs 10-12).

Fluoroalkene $\mathrm{CH}_{2}=\mathrm{CHCH}_{2}-n-\mathrm{C}_{4} \mathrm{~F}_{9}(\mathbf{1 b})$ bearing a shorter fluoroalkyl-chain was similarly copolymerized with $\mathrm{CO}$ ( $27 \%$ yield under the same condition as run 9). It should be noted that the fluoroalkenes $\mathbf{1 a}$ and $\mathbf{1 b}$ are much less active than simple aliphatic 1-alkenes. For example, 1-hexene (1c) copolymerizes with $\mathrm{CO}$ in the much shorter time of $45 \mathrm{~min}$ under otherwise identical conditions to give the copolymer in $58 \%$ yield.

The polymer obtained from $\mathbf{1 a}$, that is poly $(\mathbf{1} \mathbf{a}-$ alt $-\mathrm{CO})$, was not soluble in any of the common organic solvents. Thus, the materials obtained in Table 1 were characterized by IR and NMR spectroscopies and MALDI-TOF mass spectrometry. While the copolymer obtained from 1a was a mixture of polyketone and spiroketal, the one from $\mathbf{1 b}$ had a complete spiroacetal form (Scheme 3). The coexistence of ketone structure and spiroketal structure for poly (1a-alt$\mathrm{CO})$ may be explained by the longer perfluoroalkyl group in 1a causing the aggregation of fluorous groups, partially overcoming the demand by the main-chain to form the spiroketal structure.

Scheme 3. Spiroketal formation.

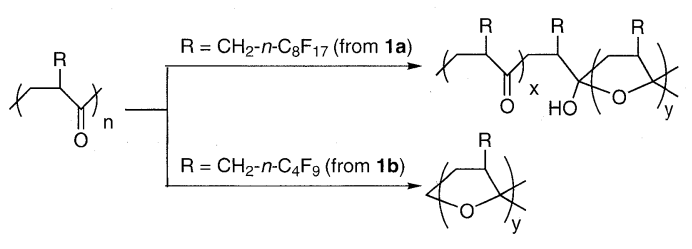

In order to clarify the polymerization mechanism, the reaction of acetylpalladium with $\mathrm{CH}_{2}=\mathrm{CHCH}_{2} \mathrm{C}_{8} \mathrm{~F}_{17}$ (1a) in the absence of CO was monitored for DPPP (2a), BINAPHOS (2e), and MeDuPHOS (2f) (Scheme 4). With ligand 2a, alkyl complex 3a(2,1) was observed as a single product via the 2,1-insertion of olefin 1a. On the contrary, the alkyl complex bearing ligand $2 \mathrm{e}$ was detected as a mixture and the two major species were assigned to isomers of the 1,2-adducts; namely $3 \mathrm{e}(1,2) \mathrm{OP}-$ trans $^{-} \mathrm{CO}$ and $\mathbf{3 e}(1,2) \mathrm{OP}-$ $c i s-\mathrm{CO}$. In the absence of $\mathrm{CO}, \beta$-hydride elimination from 1,2 -inserted complexes $3 \mathbf{e}$ resulted in the formation of $\alpha, \beta$ unsaturated ketones 4, 4', and 5: $\mathbf{4}$ and its reduced compound 4' were produced while a mixture of $\mathbf{5}$ and $\mathbf{4}^{\prime}\left(\mathbf{5} / \mathbf{4}^{\prime}=82 / 18\right)$ accompanied by a trace amount of $\mathbf{4}$. Thus, it can be further confirmed that olefin 1a insertion takes place exclusively via 2,1-insertion with ligand $\mathbf{2 a}$ while $\mathbf{1 a}$ insertion proceeds via both 1,2- and 2,1-fassion with ligand 2e, the 1,2-insertion being the major pathway.

The result seems closely related to the selective 1,2-insertion of styrene to acyl complex $\left[\mathrm{CH}_{3} \mathrm{C}(=\mathrm{O}) \mathrm{Pd}(\mathrm{NCMe})(\mathbf{2 e})\right]^{+}$$[\mathrm{BArF}]^{-}$(Scheme 5). ${ }^{17}$ The palladium-catalyzed styrene/CO copolymerization usually requires the use of bidentate $\mathrm{sp}^{2}-$ nitrogen ligands and ligand $2 \mathbf{e}$ is the only exception among bidentate phosphorus ligands in terms of its effectiveness for the styrene/CO cooligomerization. ${ }^{2 b, 18}$ The bulky ligand $2 e$ preferred the 1,2 -insertion to the $2,1-$, so that the steric 
Scheme 4. The reactions of acetylpalladium complexes 2 with one equivalent of $\mathrm{CH}_{2}=\mathrm{CHCH}_{2} \mathrm{C}_{8} \mathrm{~F}_{17}(\mathbf{1 a})$. Counter anions $\left(\mathrm{BAr}^{\mathrm{F}}\right)$ are omitted for clarity.

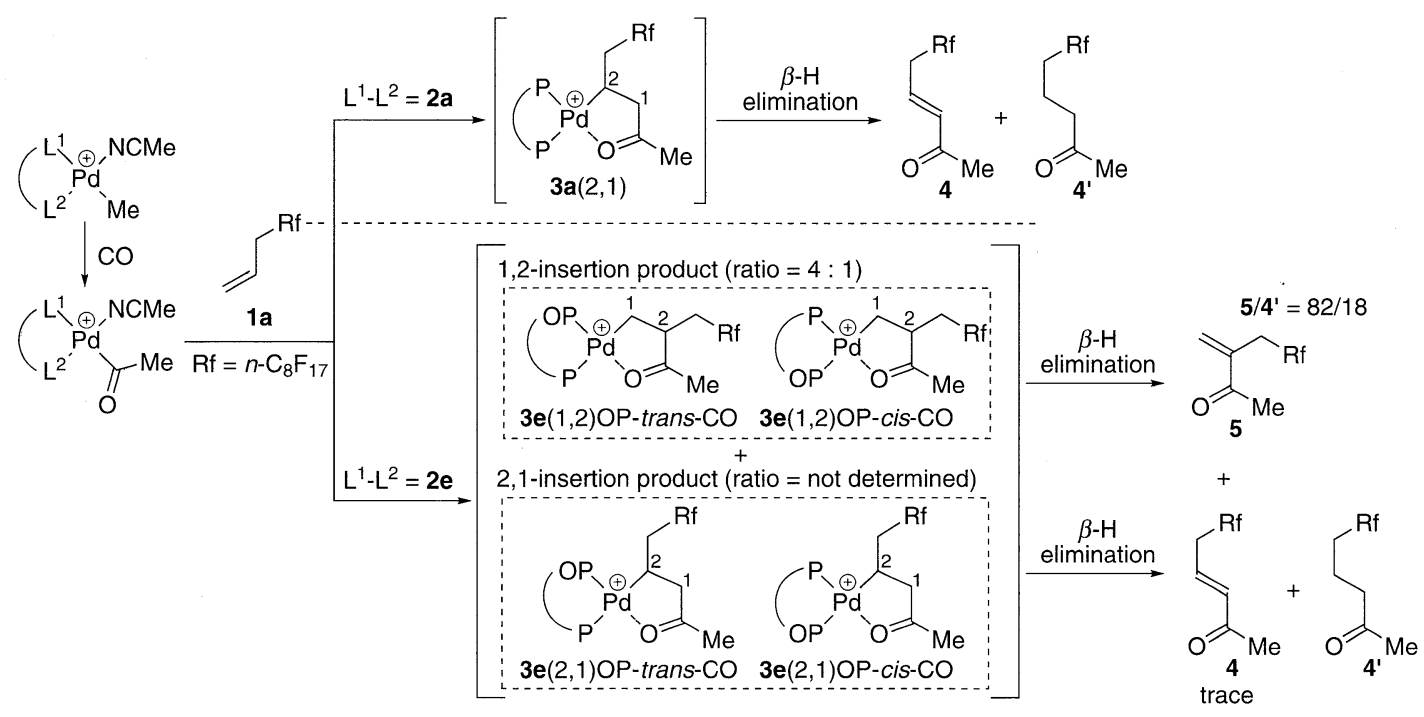

Scheme 5. Characteristic 1,2-insertion of styrene to acetylpalladium complex bearing BINAPHOS ligand.

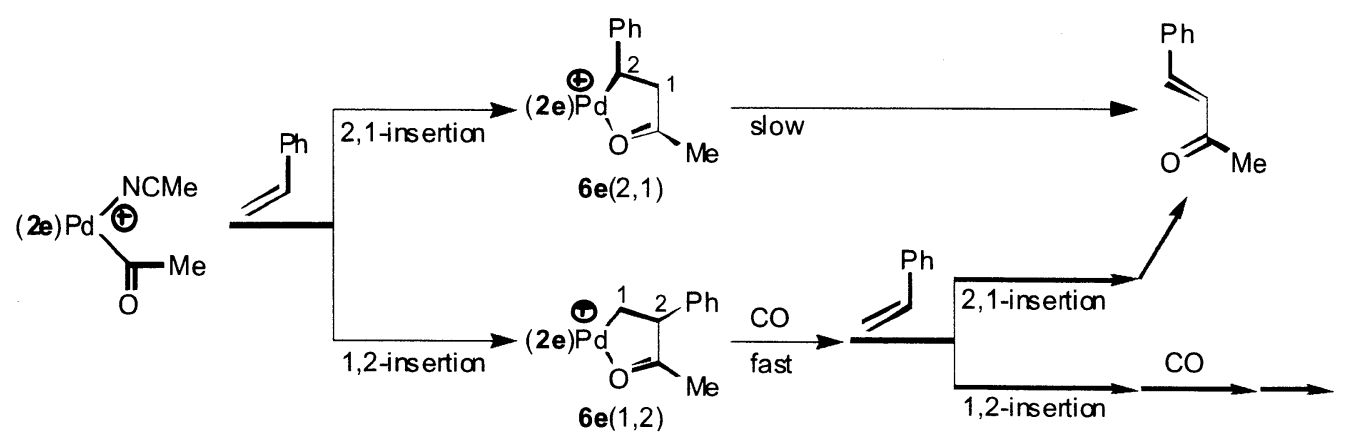

repulsion between the ligand and the phenyl group of styrene would be avoided. The unique styrene/CO cooligomerization with $2 \mathrm{e}$ was thus attributed to the facile $\mathrm{CO}$ insertion in the $1,2-$ adduct $6 \mathbf{e}(1,2)$. It was also suggested that there was occasional 2,1-insertion of styrene which ended up in the $\beta$ hydride elimination. Similarly with fluoroalkene 1a, the $2,1-$ product such as $\mathbf{3 a}(2,1)$ seems to be the "dead end" which is not involved in further polymerization.

The different reactivity between the 1,2-adduct and the 2,1-adduct should arise from either the step C to D (carbonyl coordination) or $\mathbf{D}$ to $\mathbf{A}$ (carbonyl insertion) in Scheme 1. Alkylpalladium $\mathbf{C}$ bearing $\mathrm{CH}_{2}-n-\mathrm{C}_{8} \mathrm{~F}_{17}$ on the $\alpha$-carbon to palladium $(=2,1$-adduct $)$ is likely to form a stronger fivemembered chelation by lowering the electron density of the palladium center. The CO-coordination $\mathbf{C} \rightarrow \mathbf{D}$ should become less favorable with the stronger chelation. In addition, the electron deficient $\alpha$-carbon in $\mathbf{D}$ should retard the subsequent insertion of $\mathrm{CO}$ to the metal-carbon bond ( $\mathbf{D} \rightarrow$ A) by lowering the nucleophilicity of the migrating $\alpha$-carbon atom. Such an electronic disadvantage of the $\mathrm{CH}_{2}-n-\mathrm{C}_{8} \mathrm{~F}_{17}$ group is successfully avoided in the 1,2-adduct. In other word, the electron-withdrawing substituent is on the $\beta$-position of the palladium and the $\alpha$-carbon is less electron deficient.

\section{The Alternating Copolymerization of Vinyl Acetate with Carbon Monoxide}

Coordination polymerization of readily-available polat vinyl monomers has been one of the major challenges in the field of olefin polymerization for decades. Among polar vinyl monomers, vinyl acetate has been the most challenging target. Vinyl acetate is one of the most readily-available and widely-used polar vinyl monomers for polymer production. Nearly five million tons of vinyl acetate is produced worldwide each year. ${ }^{19}$ However, unlike most of the other monomers, ${ }^{20}$ vinyl acetate has been recognized as unique in the sense that the only way to polymerize it is a radical process. $^{21}$ Neither anionic, cationic or coordination polymerization has been efficiently applied to vinyl acetate.

We obtained the alternating copolymer of vinyl acetate with $\mathrm{CO}$ by using a mixture of $\mathrm{Pd}$ (dibenzylideneacetone) $)_{2}$ (= $\left.\mathrm{Pd}(\mathrm{dba})_{2}\right)$ and phosphine-sulfonic acid ligand (7a). ${ }^{22}$ The ligand employed here was originally reported by a group from Shell for the non-perfectly alternating copolymerization of ethylene with carbon monoxide. ${ }^{23}$ When vinyl acetate was treated with $6.0 \mathrm{MPa}$ of $\mathrm{CO}$ at $70{ }^{\circ} \mathrm{C}$ for 20 hours in the presence of $\mathrm{Pd}(\mathrm{dba})_{2}$ and $\mathbf{7 a}$ as a catalyst, the corresponding alternating copolymer with $M_{\mathrm{n}}$ of 38,000 was obtained with an activity of $2.3 \mathrm{~g} \cdot \mathrm{mmol}^{-1} \cdot \mathrm{h}^{-1}$ (Table 2 , run 1 ). Higher activity and molecular weights of the copolymers were 
Table 2. Alternating copolymerization of vinyl acetate and $\mathrm{CO}^{\mathrm{a}}$.

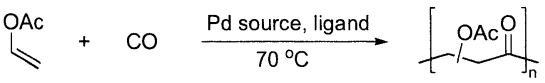

$$
\begin{aligned}
& \overbrace{\mathrm{SO}_{3}^{\ominus}}^{\stackrel{\oplus}{\mathrm{PHAr}}}
\end{aligned}
$$

7a: $\mathrm{Ar}=\mathrm{o}-\mathrm{MeOC}_{6} \mathrm{H}_{4}$

$7 \mathrm{~b}: \mathrm{Ar}=\mathrm{Ph}$

\begin{tabular}{cccccccc}
\hline run & Pd source & ligand & $\begin{array}{c}\text { time } \\
(\mathrm{h})\end{array}$ & $\begin{array}{c}\mathrm{TOF} \\
\left(\mathrm{h}^{-1}\right)\end{array}$ & $\begin{array}{c}\text { activity } \\
\left(\mathrm{g} \cdot \mathrm{mmol}^{-1} \cdot \mathrm{h}^{-1}\right)\end{array}$ & $\begin{array}{c}M_{\mathrm{n}} \\
\left(\times 10^{3}\right)\end{array}$ & $M_{\mathrm{w}} / M_{\mathrm{n}}$ \\
\hline 1 & $\mathrm{Pd}(\mathrm{dba})_{2}$ & $\mathbf{7 a}$ & 20 & 20 & 2.3 & 38 & 1.4 \\
2 & $\mathrm{Pd}(\mathrm{dba})_{2}$ & $\mathbf{7 b}$ & 20 & 9.2 & 1.1 & 26 & 1.3 \\
3 & $\mathrm{Pd}(\mathrm{dba})_{2}$ & $7 \mathbf{a}$ & 1.0 & 24 & 2.7 & 4.9 & 1.1 \\
4 & $\mathrm{Pd}(\mathrm{dba})_{2}$ & $7 \mathbf{a}$ & 5.0 & 26 & 3.0 & 18 & 1.2 \\
5 & $\operatorname{Pd}(\mathrm{dba})_{2}$ & $7 \mathbf{a}$ & 70 & 7.6 & 0.87 & 41 & 1.7 \\
6 & $\operatorname{Pd}(\mathrm{OAc})_{2}$ & $7 \mathbf{a}$ & 20 & 9.2 & 1.1 & 34 & 1.4 \\
\hline
\end{tabular}

${ }^{a}$ Conditions: $0.010 \mathrm{mmol}$ of Pd source, $0.012 \mathrm{mmol}$ of ligand, $6.0 \mathrm{MPa}$ of CO pressure, $2.5 \mathrm{~mL}$ of vinyl acetate, $70{ }^{\circ} \mathrm{C}$. ${ }^{\mathrm{b}} 0.050 \mathrm{mmol}$ of galvinoxyl was added.

achieved with the methoxy-substituted ligand $7 \mathbf{a}$, rather than unsubstituted one $7 \mathbf{b}$ (runs 1 and 2).

The structure of the alternating copolymers was confirmed by mass spectrometry and NMR spectroscopy. The head-to-tail structure is suggested to be less controlled based on the existence of multiple peaks for methyne and methylene of the main-chain in both ${ }^{1} \mathrm{H}$ and ${ }^{13} \mathrm{C}$ NMR spectra.

A possible mechanism of the alternating copolymerization is shown in Figure 2 (a). Oxidative addition of $\operatorname{Pd}(0)$ to
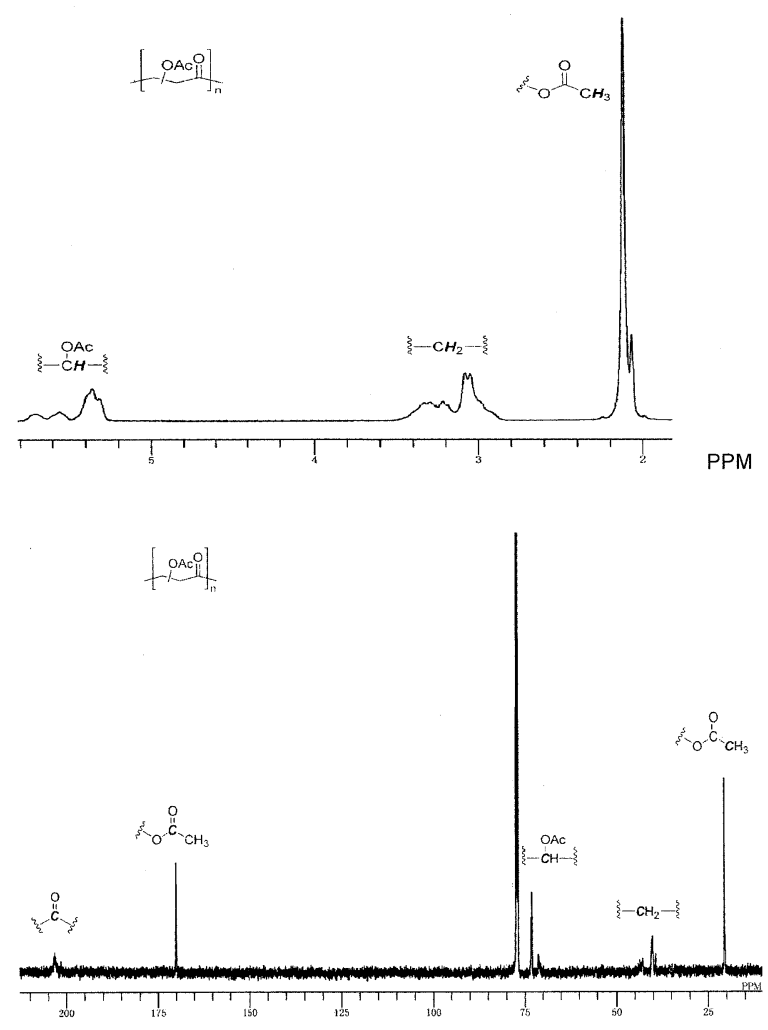

Figure 1. ${ }^{1} \mathrm{H}$ and ${ }^{13} \mathrm{C}$ NMR spectra of poly (vinyl acetate-alt-carbon monoxide). the sulfonic acid gives $\mathrm{Pd}-\mathrm{H}$ species. The alternating insertion of vinyl acetate and $\mathrm{CO}$ resulted in the production of the copolymer. The 2,1-insertion occurred more frequently than 1,2-insertion, as was confirmed by end-group analysis by ${ }^{1} \mathrm{H}$ NMR. The 2,1-insertions were also theoretically predicted ${ }^{24}$ and experimentally observed in other systems. ${ }^{11 a}$ The 2,1 -insertion product forms a stable five-membered chelate, into which only $\mathrm{CO}$ can be inserted. The fact that we obtained the copolymer corresponds the fact that vinyl acetate, which was anticipated to have a low coordinating ability with the carbon-carbon double bond, ${ }^{7}$ did coordinate with the palladium center and inserted to the acylpalladium bond.

In order to further clarify the reaction mechanism, alkylpalladium species $\mathbf{8 b}$ was synthesized from anionic methylpalladium complex ${ }^{25}$ and vinyl acetate (Scheme 6). When 1-acetoxypropylpalladium $\mathbf{8 b}$ was employed as an initiator for the copolymerization, the 1 -acetoxypropyl group was observed by ${ }^{1} \mathrm{H}$ NMR to be the initiating end group, instead of 1-acetoxyethyl group as shown in Figure 2 (b). Copolymerization with $\mathbf{8 b}$ showed higher activity than the mixture of $\mathbf{7 b}$ and $\operatorname{Pd}(\mathrm{dba})_{2}$, suggesting efficient initiation of the copolymerization with $\mathbf{8 b}$. The major series of peaks on the MALDI-TOF mass spectrum of the copolymer obtained with $\mathbf{8 b}$ were assigned to a completely alternating copolymer initiated by insertion of $\mathrm{CO}$ to 1-acetoxypropylpalladium and removed from the metal by protonolysis of alkylpalladium resulting

Scheme 6. Preparation of initiator $\mathbf{8 b}$.

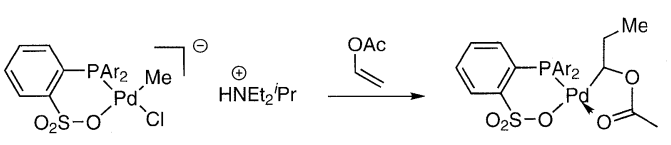

$8 b$

(a)
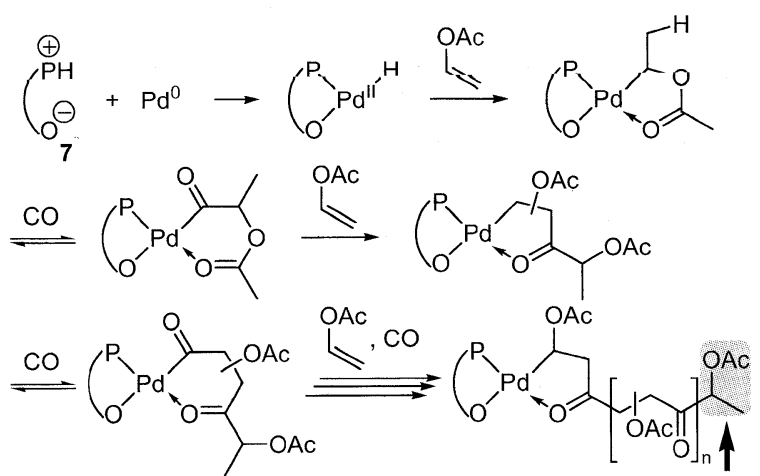

(b)

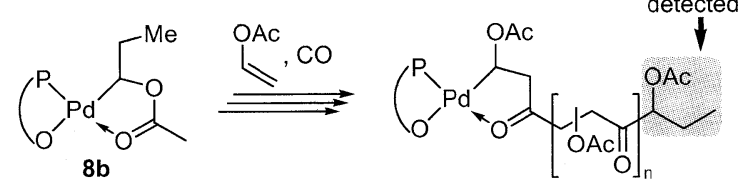

Figure 2. A possible mechanism of copolymerization of vinyl acetate and $\mathrm{CO}$ initiated and catalyzed by (a) 7 and $\mathrm{Pd}(\mathrm{dba})_{2}$, or (b) $\mathbf{8 b}$. 
from the last insertion of vinyl acetate.

Polymerization via radical intermediates is unlikely, based on the following observations. Copolymerization using catalyst $\mathbf{8 b}$ in the presence of galvinoxyl, a well-known radical trap, showed similar activity and provided the copolymer with a similar molecular weight of 25,000 . When an radical initiator AIBN was used instead of the Pd catalyst, poly(vinyl acetate) was obtained as a sole product. Therefore, we believe a coordination-insertion mechanism operates for the copolymerization as observed with other Pd-catalyzed alternating copolymerization of alkenes with carbon monoxide.

The reason is not clear yet, as to why this particular ligand system could overcome the low coordination ability of vinyl acetate. However, this might be related to the fact that the non-alternating copolymer of ethylene with $\mathrm{CO}$ was given by using ligand $7 \mathbf{7 a}{ }^{23}$ In the alternating copolymerization with conventional ligands, the five-membered chelate $\mathbf{C}$ in Scheme 1 is too strong for ethylene to coordinate with the palladium and get inserted into the alkylpalladium bond. This was interpreted as the reason for the alternating nature for olefin/CO copolymerization. It is of interest to note that ligand $7 \mathbf{a}$ overcame the low coordinating ability of a $\mathrm{C}-\mathrm{C}$ double bond, both in the non-alternating ethylene/CO copolymerization and in the vinyl acetate/CO copolymerization.

\section{Conclusion}

Two examples of "unusual" alternating copolymerization of olefins with $\mathrm{CO}$ have been introduced. It should be noted that even using the same palladium metal as a center metal for catalysis, the choice of ligands strongly affect the polymerization results. Further studies are required to clarify the role played by the ligands, especially for ligand $7 \mathbf{a}$.

\section{Acknowledgments}

The work here summarized was achieved in collaboration with Drs. T. Kochi, K. Nakano, and M. Yamashita and graduate students T. Fujita and A. Nakamura at the University of Tokyo.

\section{References}

1) (a) Functional Polymers: Modern Synthetic Methods and Novel Structures. A. O. Patil, D. N. Schulz, B. M. Novak, Eds., ACS Symposium Series 704 (American Chemical Society, Washington, DC, 1998) (b) Boffa, L. S.; Novak, B. M. Chem Rev. 2000, 100, 1479. (c) Mecking, S.; Johnson, L. K.; Wang, L.; Brookhart, M. J. Am. Chem. Soc. 1998, 120, 888.

2) (a) Catalytic Synthesis of Alkene-Carbon Monoxide Copolymers and Cooligomers. A. Sen, Ed., (Kluwer Academic Publishers, Dordrecht, The Netherlands, 2003. (b) Drent, E.; Budzelaar, P. H. M. Chem. Rev. 1996, 96, 663. (c) Bianchini, C.; Meli, A. Coord. Chem. Rev. 2002, 225, 35.

3) Kacker, S.; Jiang, Z. Z.; Sen, A. Macromolecules 1996, $29,5852$.

4) Lee, J. T.; Alper, H. Chem. Commun. 2000, 2189.

5) Murtuza, S.; Harkins, S. B.; Sen, A. Macromolecules 1999, 32, 8697.

6) Nozaki, K.; Shibahara, F.; Elzner, S.; Hiyama, T. Can. J. Chem.
2001, 79, 593.

7) Williams, B. S.; Leatherman, M. D.; White, P. S.; Brookhart, M. J. Am. Chem. Soc. 2005, 127, 5132.

8) Foley, S. R.; Stockland, Jr. R. A.; Shen, H.; Jordan, R. F. J. Am. Chem. Soc. 2003, 125, 4350 .

9) Wu, F.; Foley, S. R.: Burns, C. T.; Jordan, R. F. J. Am. Chem. Soc. 2005, 127, 1841 .

10) (a) Rix, F. C.; Brookhart, M.; White, P. S. J. Am. Chem. Soc. 1996, 118, 4746. (b) Braunstein, P.; Frison, C.; Morise, X. Angew. Chem.-Int. Edit. 2000, 39, 2867.

11) (a) Reddy, K. R.; Chen, C. L.; Liu, Y. H.; Peng, S. M.; Chen, J. T.; Liu, S. T. Organometallics 1999, 18, 2574. (b) Reddy, K. R.; Surekha, K.; Lee, G. H.; Peng, S. M.; Chen, J. T.; Liu, S. T. Organometallics 2001, 20, 1292.

12) Shen, H.; Jordan, R. F. Organometallics 2003, 22, 1878.

13) Foley, S. R.; Shen, H.; Qadeer, U. A.; Jordan, R. F. Organometallics 2004, 23, 600 .

14) Fujita, T.; Nakano, K.; Yamashita, M.; Nozaki, K. J. Am. Chem. Soc. 2006, 128, 1968

15) Brandstrom, A. J. Chem. Soc. Perkin Trans. 2 1999, 1855.

16) Korenaga, T.; Kadowaki, K.; Ema, T.; Sakai, T. J. Org. Chem. 2004, 69, 7340.

17) (a) Nozaki, K.; Komaki, H.; Kawashima, Y.; Hiyama, T.; Matsubara, T. J. Am. Chem. Soc. 2001, 123, 534. (b) Iggo, J. A.; Kawashima, Y.; Liu, J.; Hiyama, T.; Nozaki, K. Organometallics 2003, 22, 5418 .

18) Brookhart, M.; Rix, F. C.; Desimone, J. M.; Barborak, J. C. J. Am. Chem. Soc. 1992, 114, 5894.

19) Gustin, J.-L.; Laganier, F. Org. Process Res. Dev. 2005, 9, 962.

20) For vinyl chloride, (a) Endo, K.; Kaneda, N.; Waku, H. Polymer 1999, 40, 6883. (b) Endo, K.; Saitoh, M. J. Polym. Sci. Part A. 2003, 41, 248.

21) Koumura, K.; Satoh, K.; Kamigaito, M.; Okamoto, Y. Macromolecules 2006, 39, 4054.

22) Kochi, T.; Nakamura, A.; Ida, H.; Nozaki, K. J. Am. Chem. Soc. 2007, 129, 7770.

23) Drent, E.; van Dijk, R.; van Ginkel, R.; van Oort, B.; Pugh, R. I. Chem. Commun. 2002, 964.

24) Philipp, D. M.; Muller, R. P.; Goddard, III, W. A.; Storer, J.; McAdon, M.; Mullins, M. J. Am. Chem. Soc. 2002, 124, 10198.

25) Kochi, T.; Yoshimura, K.; Nozaki, K. Dalton Trans. 2006, 25.

\section{PROFILE}

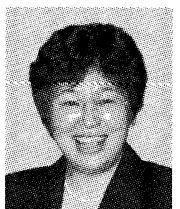

Kyoko Nozaki is Professor of The University of Tokyo. She received her Ph.D. from Kyoto University in 1991. After her $\mathrm{PhD}$, she worked as a research associate and was appointed to be Associate professor at Kyoto University in 1999. In 2002, she moved to The University of Tokyo where she was promoted to a full professor of Chemistry and Biotechnology in 2003. Her research interest concerns the development of homogeneous catalysis for stereocontrol in organic synthesis and polymer synthesis. Her accomplishments include Pfizer Award for Young Chemists in Synthetic Organic Chemistry, Japan (1994), the Chemical Society of Japan Award for Young Chemists (1998), OMCOS prize in organometallic chemistry (2003), SPSJ Wiley Award (2004), and Japan IBM Award for Science (2006). 